\title{
Puncture Collimator for the Laue Back Reflection Technique
}

\section{Lindegaard-Andersen, Asger}

\section{Published in:}

Review of Scientific Instruments

Link to article, DOI:

$10.1063 / 1.1683087$

Publication date:

1968

Document Version

Publisher's PDF, also known as Version of record

Link back to DTU Orbit

Citation (APA):

Lindegaard-Andersen, A. (1968). Puncture Collimator for the Laue Back Reflection Technique. Review of Scientific Instruments, 39(1), 124-125. https://doi.org/10.1063/1.1683087

\section{General rights}

Copyright and moral rights for the publications made accessible in the public portal are retained by the authors and/or other copyright owners and it is a condition of accessing publications that users recognise and abide by the legal requirements associated with these rights.

- Users may download and print one copy of any publication from the public portal for the purpose of private study or research.

- You may not further distribute the material or use it for any profit-making activity or commercial gain

- You may freely distribute the URL identifying the publication in the public portal

If you believe that this document breaches copyright please contact us providing details, and we will remove access to the work immediately and investigate your claim 


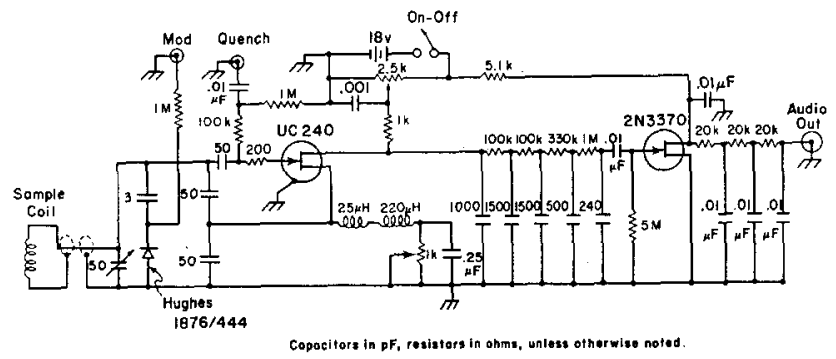

FIG. 1. Circuit of the FET oscillator-detector. The oscillator gate is shunted to ground by a megohm resistor to prevent transients and static charges accumulating at the very high input impedance gate of the FET from biasing the oscillations off.

advantages associated with grounding one end of the sample coil. A varactor diode, selected for its high $Q$, provides for external frequency modulation and for electronic frequency sweep.

The circuit was first tested and adjusted with weakly coupled external signals from a test oscillator, then with quadrupole resonances of various compounds over the frequency range from 1-40 $\mathrm{MHz}$. At $30 \mathrm{MHz}$, for example, with $20 \mathrm{kHz}, 6 \mathrm{~V}$ peak-to-peak, square or sine wave quenching, a $2.5 \mu \mathrm{V}$ signal applied to the tank through a $1 \mathrm{pF}$ capacitor, produces a $1: 1 \mathrm{~S} / \mathrm{N}$ ratio at the output of the audio amplifier stage. Chlorine and nitrogen resonances have been observed, as shown in Fig. 2.

Comparisons with a self-quenched Nuvistor circuit ${ }^{3}$ constructed in this Laboratory indicated similar signal-tonoise ratios. It is interesting that in normal operation no

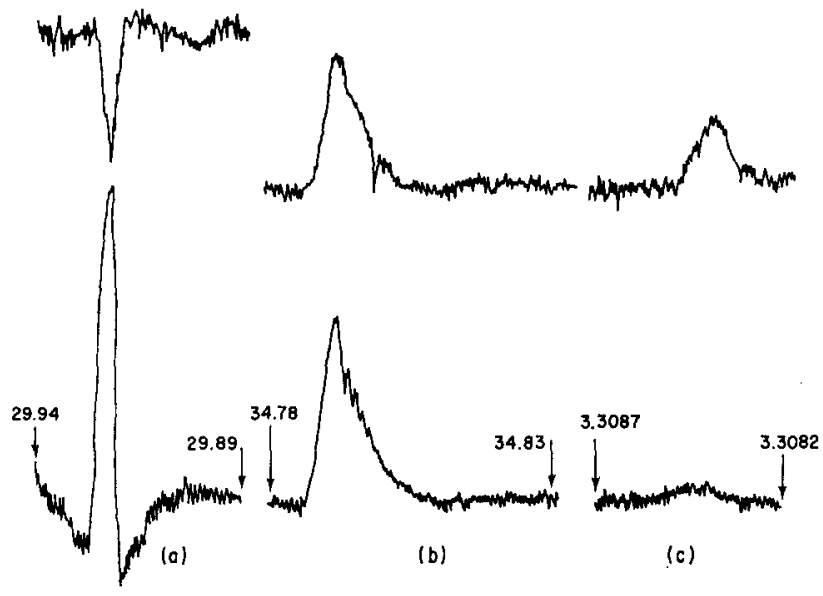

FIG. 2. Typical spectra observed with the circuit-(a) $\mathrm{NaClO}_{\mathbf{a}}$ at room temperature, (b) paradichlorobenzene at $77^{\circ} \mathrm{K}$, and (c) hexamethylenetetramine at room temperature. Numbers are frequencies in megahertz. Sample volumes were about $3 \mathrm{cc}$ for $\mathrm{Cl}$ compounds and 120 cc for $\mathrm{N}$ compounds. Antisymmetric square-wave Zeeman modulation was used at about $9 \mathrm{G}$ for $\mathrm{NaClO}_{3}, 36 \mathrm{G}$ for the paradichlorobenzene, and $8 \mathrm{G}$ for the hexamethylenetetramine. The traces above and below were recorded using the two channels of a dual channel synchronous detector, Princeton Applied Research model JB-6 in quadrature with each other, and of arbitrary phase with respect to the modulating field. The time constants were $1 \mathrm{sec}$ and the signal frequency was $100 \mathrm{~Hz}$. side bands were seen, although the oscillator spectrum, as viewed with a Tektronix IL-20 spectrum analyzer, ${ }^{4}$ showed normal Fourier components. These results show that development of search spectrometers based on superregenerative FET circuits is feasible, and that an unexpected advantage in reduction of side-bands can be achieved.

Further tests of this circuit using the newer type 2N4416 field effect transistor showed improved signal-to-noise ratio in all modes of operation: self-quenched, logarithmic, and both slope and step controlled linear mode. ${ }^{5}$ With the narrow band detection system of Fig. 2, time constant 1 sec, the $\mathrm{NaClO}_{3}$ resonance at room temperature gave signal to noise ratio around 100 in all modes of operation except, as expected from theory, ${ }^{5}$ in step-controlled linear mode, where a signal-to-noise ratio around 30 was obtained with a line width roughly twice as great as in the slope-controlled linear case. With a $3 \mathrm{sec}$ integrating time constant, signalto-noise ratios of around $\mathbf{1 7 0}$ have been obtained in the linear mode. This is better than some comparable published spectra ( $\mathrm{S} / \mathrm{N}$ about 80 ) obtained with tube circuits. ${ }^{6}$

* This research was supported by a Grant-in-Aid from the U. S. Public Health Service, Research Grant GM 1208202 from the National Institute of General Medical Sciences.

1 J. M. Cohen, Electronics 37, 62 (30 Nov. 1964).

2 B. Smith, Electronics 37, 58 (14 Dec. 1964).

'C. T. O'Konski and T. J. Scheffer, note in'preparation for Rev. Sci. Instr.

4 We are happy to acknowledge Ioan of a Tektronix IL-20 spectrum analyzer through the courtesy of Paul Magnuson.

6 J. R. Whitehead, Super-Regenerative Receivers (Cambridge University Press, Cambridge, 1950).

- See, e.g., D. Williams, Methods in Experimental Physics III (Academic Press Inc, New York, 1962), p. 511.

\section{Puncture Collimator for the Laue Back Reflection Technique}

\author{
A. LindegaARd ANDersen \\ Physics Laboratory III, Technical University \\ of Denmark, Lyngby, Denmark
}

(Received 27 April 1967)

T $\mathrm{N}$ determination of crystal orientation by the Laue $\mathrm{x}$-ray back reflection method, it is often convenient to record reflections from lattice planes closely normal to the incident beam. This is not possible by the usual technique where a hole of 5 to $10 \mathrm{~mm}$ in diameter is cut in the film for the passage of the incident beam. The diameter of the indispensable hole in the film can be reduced to about $1 \mathrm{~mm}$ by application of the "puncture collimator" illustrated in Fig. 1. The puncture tube has been made from a $1 \mathrm{~mm}$ steel tube with an $0.5 \mathrm{~mm}$ bore and adapted to a conventional collimator. The puncture tube easily perforates the film and the cover paper, cutting a $1 \mathrm{~mm}$ circular hole in the film. In order to avoid the entrance of light to the film, a small rubber sheet is glued to the cover 
Frg. 1. Puncture collimator for the Laue back reflection technique.

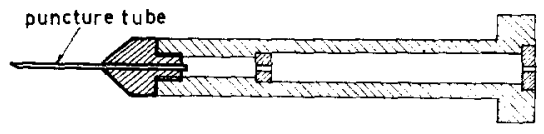

paper at the penetration point of the tube. The application of the puncture collimator facilitates precise determination of crystal orientation. This is due to the fact that the penetration point of the incident beam on the film is well defined as the center of the $1 \mathrm{~mm}$ circular hole. With crystals of good quality, the puncture collimator yields small, well defined reflection spots, and the orientation can be determined with an accuracy better than $0.1^{\circ}$.

\section{Highly|Reflective, Adherent, Thick Aluminum Films on Glass}

\author{
E. L. Bahm, I. C. Peabody, and W. Vedder \\ General Electric Research and Development Center, \\ Schenectady, New York 12301
}

(Received 3 October 1967)

$\mathrm{F}^{\mathrm{o}}$ R a spectroscopic study of chemical and anodic oxidation of aluminum, we desired to reproducibly evaporate onto thin glass slides highly reflective films of aluminum of about $1 \mu$ thickness. We further required that these films be capable of withstanding a standard tape test and that they can be boiled in distilled water for at least $\frac{1}{2} \mathrm{~h}$ with no sign of blistering or peeling. Finally it is necessary that they can be anodically oxidized to at least $200 \mathrm{~V}$. Various parameters such as substrate temperature, evaporation rate, residual gas pressure in system, and film thickness strongly influence the smoothness of evaporated films ${ }^{1}$ and their adherence to the glass. In particular a high substrate temperature seems desirable for good adherence, but detrimental to the reflectivity. Our objectives have been finally achieved by the following technique:

We use a vacuum bell jar system capable of producing a vacuum in the $10^{-8}$ Torr range. The system is equipped to

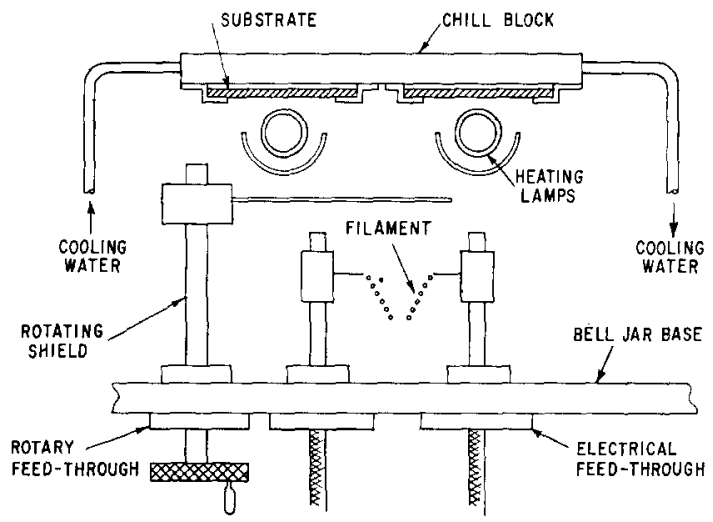

FIG. 1. Heating, cooling, and evaporation assembly. accommodate the electrical circuitry for one tungsten evaporating filament and, for the purpose of heating the glass substrates, two GE infrared quartz lamps. There are also water feedthroughs for cooling the substrates rapidly and a shutter arrangement between the filament and substrates to control evaporation.

The glass slides go through a rigorous cleaning procedure involving various steps such as washing in a hot detergent solution, rubbing with a slurry of Precisionite and water, ultrasonic and chromic acid treatments, followed by rinsing in boiling distilled water. From here on they are only handled with tweezers.

The slides to be coated are clamped to a $1.6 \mathrm{~mm}$ thick nickel plate with a spring loaded thermocouple pressing on the front surface of one of them to monitor the temperature throughout the run. This assembly is then bolted to a $3 \mathrm{~mm}$ copper plate that can be water cooled (Fig. 1).

A conical basket type tungsten filament holding about $1 \mathrm{~g}$ of very pure aluminum (about $99.999 \%$ ) is mounted on two of the electrical feedthroughs and centrally located $20 \mathrm{~cm}$ below the substrates. Two GE quartz infrared 500T3 lamps are placed about $7.6 \mathrm{~cm}$ apart and about $2.5 \mathrm{~cm}$ below the substrates and in a position so as not to obstruct the evaporation of the aluminum to the substrates.

The evaporation system is exhausted to a pressure of $10^{-6}$ Torr or better. An adjustable transformer operates the infrared lamp circuit and power is applied until the substrate temperature reaches $300^{\circ} \mathrm{C}$. This heating is maintained for $1 \mathrm{~h}$. The power is then turned off and water is circulated through the copper cooler until the substrate temperature reaches $250^{\circ} \mathrm{C}$. The reduction in temperature should be accomplished in a short time, preferably 1-2 min. Just prior to this the aluminum bearing tungsten basket evaporator is brought up to temperature. When the temperature of the substrate reaches $250^{\circ} \mathrm{C}$, the shutter is opened and a small but visible amount of aluminum is evaporated onto the substrate. The shutter is closed and

FIG. 2. Electron micrograph of evaporated aluminum film.

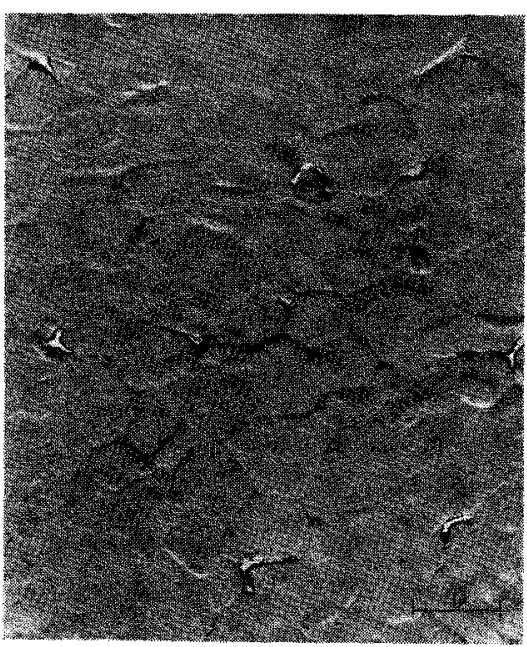

